Kidney

Blood Pressure

Research

\title{
6th Central European Meeting on Hypertension
}

October 22-25, 2011, Bratislava, Slovakia

\section{Abstracts}

Guest Editors

R. Cífková, Prague

S. Filipová, Bratislava

\section{Contents}

Abstracts 1-39 


\section{Selected Abstracts}

\section{Kidney \\ Blood Pressure \\ Research}

1

\section{Spontaneously Hypertensive Rats Benefit from Red Palm Oil Supplementation}

\author{
B. Bačová1, C. Viczencz², J. Radošinská3 , V. Knezl', \\ I. Bernatová ${ }^{5}$ V. Sotniková4 , J. Navarová4, J. van Rooyen ${ }^{5}$, \\ N. Tribulová \\ ${ }^{1}$ Institute of Heart Research, Slovak Academy of Sciences, \\ ${ }^{2}$ Faculty of Natural Sciences, Comenius University, \\ ${ }^{3}$ Institute of Physiology, Faculty of Medicine, Comenius \\ University, ${ }^{4}$ Institute of Experimental Pharmacology and \\ Toxicology, ${ }^{5}$ nstitute of Normal and Pathological \\ Physiology, Slovak Academy of Sciences, Bratislava, \\ Slovakia
}

Background: Spontaneously hypertensive rats (SHR) that mimic human essential hypertension have been previously shown to benefit from omega-3 unsaturated fatty acids supplementation that is salutary in clinic as well. Recently, the cardioprotective effect of red palm oil (RPO) containing 50\% saturated fatty acids, carotenoids, tocoferol, and tocotrienols has been reported. The purpose of this study was to examine the effects of RPO supplementation in SHR. Design and Methods: SHR and WKY rats fed a standard rat chow plus RPO (200 microL/day) for 5 weeks were compared with untreated controls. Systolic blood pressure (SBP), plasma cholesterol $(\mathrm{CH})$, triglycerides $(\mathrm{TG})$, and blood glucose $(\mathrm{BG})$ were registered at the end of experiment. Nitric oxide synthase (NOS) activity was determined in the left ventricle and aorta, whose function was also examined. Isolated perfused heart was used for the examination of post-ischemic reperfusion-induced arrhythmias and electrically inducible ventricular fibrillation (VF). Results: RPO significantly reduced $\mathrm{BP}(160 \pm 13$ vs. $184 \pm 20 \mathrm{mmHg})$ in SHR and BG in both SHR and WKY $(4.48 \pm 0.2$ vs. $5.61 \pm 1.1$ and $5.5 \pm 0.4$ vs. $6.38 \pm 0.8$ $\mathrm{mmol} / \mathrm{L}$ ). While there were no significant differences in plasma $\mathrm{CH}$ and TG among the groups, body and heart weights were not affected by RPO as well. Compared to WKY rats, the activity of NOS was higher in SHR heart and aorta $(4.67 \pm 0.3$ and $3.18 \pm 0.5$ vs. $3.02 \pm$ 0.3 and $1.54 \pm 0.1 \mathrm{pmol} / \mathrm{mg} / \mathrm{min}$ ). RPO reduced NOS activity in the heart of both SHR and WKY rats but increased in the aorta and suppressed its relaxation. Duration of reperfusion-related bradykardia was markedly shorter in SHR vs. WKY and prolonged due to RPO, which also significantly suppressed reperfusion-induced arrhythmias and the incidence of electrically-induced VF in both strains. Conclusions: Results suggest an antihypertensive effect of RPO supplementation as well as its tissue-specific beneficial effects that challenge to elucidate possible mechanisms involved.

Supported by VEGA grants 2/0049/09 and 2/0084/10.

\section{2 \\ Effect of Chronic Red Wine Concentrate Administration on Endothelial Function in Wistar-Kyoto and Spontaneously Hypertensive Rats}

\author{
P. Bališ, A. Púzserová, P. Slezák, O. Pecháňová, I. Bernátová \\ Institute of Normal and Pathological Physiology, Slovak \\ Academy of Sciences, Bratislava, Slovakia
}

The present study investigated the effects of red wine polyphenolic concentrate (Slovinol) on blood pressure (BP) and vascular function in Wistar-Kyoto (WKY) and spontaneously hypertensive rats (SHR). Young (6-week-old) male WKY and SHR rats were divided into two groups: a control group and a group treated with Slovinol (1 $\mathrm{ml} / \mathrm{kg} /$ day) for 3 weeks. Slovinol was administered in drinking water. Blood pressure was determined by tail-cuff method. Three weeks of Slovinol administration failed to alter BP vs. the control groups. Vascular function was investigated in rings of the femoral artery (FA) using a wire myograph. Endothelium-dependent relaxation was evaluated as the responses of serotonin - pre-contracted preparations to acetylcholine (ACh). Nitric oxide (NO)-dependent component of endothelium-dependent relaxation was investigated as a difference between ACh-induced relaxation before and after acute NG-Nitro-Larginine methyl ester (L-NAME) pre-treatment. Endotheliumdependent relaxation of the FA was reduced in control SHR vs. control WKY. The endothelium-dependent relaxation of SHR was not significantly affected by Slovinol compared to controls, but was decreased in WKY; a statistical difference between WKY control and WKY Slovinol groups was found at two concentrations of ACh (out of nine). The NO-dependent component of ACh-induced relaxation was similar in all groups investigated. Slovinol had no significant effect on endothelium-independent sodium nitroprusside-induced relaxation of the FA. Moreover, Slovinol had no effect on serotonininduced vasoconstriction (with or without acute L-NAME). In conclusion, Slovinol failed to affect BP and vasorelaxation in the femoral arteries of SHR rats.

Supported by APVV-0538-07 and APVV-0523-10.

\begin{tabular}{ll}
\hline KARGER & (c) 2011 S. Karger AG, Basel \\
1420-4096/11/0352-0090 \$38.00/0 \\
$\begin{array}{l}\text { Fax +4161306 1234 } \\
\begin{array}{l}\text { E-Mail karger@karger.ch } \\
\text { www.karger.com }\end{array}\end{array}$ & $\begin{array}{l}\text { Accessible online at: } \\
\text { www.karger.com } / \mathrm{kbr}\end{array}$
\end{tabular}




\section{4}

\section{Hypertension-Induced Gap Junction Remodelling That Facilitates Malignant Arrhythmias Can Be Attenuated by Dietary Omega-3 Fatty Acids}

\section{T. Beňová, J. Radošinská, B. Bačová, V. Knezl, J. Slezák, N. Tribulová \\ Institute for Heart Research, Slovak Academy of Sciences, Bratislava, Slovakia}

Background and Purpose: Hypertension is a crucial risk factor for heart failure and sudden cardiac death, while the role of cellto-cell communication is not fully elucidated. Cardiac gap junctions (GJs) ensure, via connexin (Cx) channels, electrical and molecular signal propagation between cardiomyocytes that is necessary for synchronized heart function. On the other hand, altered GJ localisation and/or Cx channels dysfunction have been implicated in the occurrence of life-threatening arrhythmias and heart failure. We investigated the myocardial topology of GJ and distribution of dominant $\mathrm{Cx} 43$ in two experimental models of genetically-induced hypertension, i.e. spontaneously hypertensive rats (SHR) and heredidary hypertensive and hypertriglyceridemic rats (HTG) as well as the effects of omega-3 fatty acid (FA) diet and susceptibility of the heart to ventricular fibrillation (VF). Design and Methods: Left ventricular tissue taken from male, adult untreated SHR, HTG, and agematched healthy rats as well as rats treated with omega-3 FA $(200 \mathrm{mg} /$ day for 2 months) was processed for electron microscopic examination and Cx43 immunostaining to detect subcellular localisation of GJs and myocardial Cx43 distribution. Isolated perfused heart preparation was used to examine the susceptibility of the heart to electrically-induced VF. Results showed that both hypertension and hypertriglyceridemia resulted in myocardial structural remodelling (hypertrophy and/or fibrosis) that was accompanied by abnormal GJ localisation and $\mathrm{Cx} 43$ re-distribution. It was characterized by increased numbers of side-to-side GJs and lateralisation of $\mathrm{Cx} 43$, presence of internalized annular GJs, a decreased number of end-toend type (intercalated discs-related) GJ as well as by disordered distribution and loss of $\mathrm{Cx} 43$ at the area of fibrosis. The hearts of SHR and HTG rats were much susceptible to VF when compared to healthy rats. Supplementation of diseased rats with omega-3 FA resulted in attenuation of abnormal GJ and $\mathrm{Cx} 43$ distribution (remodelling) that was associated with a significant reduction of VF. Conclusions: Results indicate that hypertension itself or in combination with hypertriglyceridemia facilitate the development of myocardial arrhythmogenic substrate, which can contribute to an increased incidence of malignant arrhythmias. There is a benefit of omega-3 FA supplementation.

Supported by VEGA 2/0049/09 and APVV SK-UA-0022-09.

\section{5}

Beneficial Effect of Red Wine Polyphenols on Blood Pressure of Chronic Social StressExposed Hypertensive Rats

\author{
I. Bernatová', A. Púzserová2, R. Andriantsitohaina, \\ M. Zeman ${ }^{4}$ \\ 1,2Institute of Normal and Pathological Physiology, Slovak \\ Academy of Sciences, Bratislava, Slovakia, ${ }^{3}$ Biologie \\ Neuro-Vasculaire Intégrée, School of Medicine, Angers, \\ France, ${ }^{4}$ Department of Animal Physiology and Ethology, \\ Faculty of Natural Sciences, Comenius University, \\ Bratislava, Slovakia
}

Chronic social stress is a risk factor in the etiology of civilization diseases including hypertension. The present study investigated the effects of red wine polyphenols (ProvinolsTM) on blood pressure (BP), nitric oxide (NO) production, and plasma corticosterone (pCort) levels in Wistar-Kyoto (WKY), borderline hypertensive (BHR) and spontaneously hypertensive (SHR) rats exposed to chronic crowding stress. BHR were F1 offspring of SHR dames and WKY sires. Adult male rats were divided into four groups: control $\left(480 \mathrm{~cm}^{2} / \mathrm{rat}\right)$, ProvinolsTM-treated $\left(20 \mathrm{mg} / \mathrm{kg} / \mathrm{day}, 480 \mathrm{~cm}^{2} / \mathrm{rat}\right)$, crowded $(200$ $\mathrm{cm}^{2} /$ rat) and crowded co-treated with ProvinolsTM for 8 weeks. Blood pressure was determined by tail-cuff plethysmography, pCort by radioimmunoassay, and NO synthase activity by conversion of $[3 \mathrm{H}]-\mathrm{L}$-arginine. Both Provinols and crowding failed to affect BP in WKY. However, crowding itself significantly elevated BP in BHR and SHR. On the other hand, Provinols itself reduced BP in BHR and SHR. In both BHR and SHR, crowding-induced elevation of BP was completely prevented by simultaneous ProvinolsTM treatment. Interestingly, both ProvinolsTM and crowding significantly elevated pCort levels in all groups of rats and the greatest levels of pCort were observed in rats simultaneously exposed to both factors. ProvinolsTM alone had no effect on NO synthase activity in the aorta, but it blunted the decrease of NO synthase activity in crowded BHR and SHR rats. The results suggest that red wine polyphenols may prevent the development of chronic social stress-induced hypertension in BHR and SHR rats via protection of vascular nitric oxide synthesis regardless of corticosterone secretion. On the other hand, results suggest caution in long-term treatment of polyphenols due to acceleration of the stress response.

Supported by grant No.VEGA 2/0084/10.

6

\section{Changes in Blood Pressure During Hemodialysis and the Following 24 Hours}

\author{
K. Bobocká, D. Eisnerová, P. Slezák, J. Kalužay, P. Pontuch \\ $\mathrm{IV}^{\text {th }}$ Department of Internal Medicine, St. Cyril and \\ Methodius University Hospital, Faculty of Medicine, \\ Comenius University, Bratislava, Slovakia
}

Introduction and Aims: Poorly controlled blood pressure (BP) contributes significantly to increased cardiovascular morbidity and mortality in high-risk patients on long-term hemodialysis (HD). BP 
readings are regularly obtained during the HD session. It was recently demonstrated that out-of-dialysis BP may provide more prognostic information on cardiovascular risk. The aim of this study was to evaluate the BP changes during HD and the subsequent 24 hours using ambulatory blood pressure monitoring (ABMP) and taking into account water balance in HD. Methods: We examined 50 patients [male/female 33/17; age 57.5 (53-63) years] on HD for 3 months. BP was measured on a non-access arm every hour during HD (H0-H4) using a digital monitor and following 24 hours by a Spacelabs 90217 monitor. BP was measured every 20 min during the daytime and every 40 min during the nighttime (23:00-06:00). The patients were allocated into 2 groups according to the arithmetic mean of two mean arterial pressure (MAP) values obtained at the start and the first hour of HD: Group A $(n=25)$, MAP < 0.02). In group A, physiologic MAP decrease (dipper) during nighttime was confirmed in $10(40 \%)$ patients, no decrease (non-dipper) in $11(44 \%)$ patients, and a BP increase (reverse dipper) in $4(16 \%)$ patients. In group B, $7(28 \%)$ dippers, $13(52 \%)$ non-dippers, and $5(25 \%)$ reverse dippers were confirmed. Conclusions: The higher MAP at the start of HD in group B patients compared to group A patients was maintained throughout the whole 4-hour duration of $\mathrm{HD}$ and the following 24 hours. However, there was only a mild decrease in MAP in group A patients and no decrease in MAP in group B patients at the end of HD compared to the start of $\mathrm{HD}$. We have not found any relationship between MAP, ultrafiltration, and interdialytic weight gain. There was a decrease in MAP during nighttime in both groups in comparison with the end of HD. In each group, no difference between MAP at the beginning and at the end of 24-h ABPM that closely followed a HD session was found. From among hemodialysis patients, approximately a half were non-dippers and a fifth reverse dippers.

\section{7 \\ Different Changes in Vascular Function and Structure After Long-Term Neuronal NO-Synthase Inhibition in Normotensive and Spontaneously Hypertensive Rats}

\author{
S. Čačányiová, M. Máleková, M. Gerová, F. Kristek \\ Institute of Normal and Pathological Physiology, Slovak \\ Academy of Sciences, Bratislava, Slovakia
}

Nitric oxide (NO) is an important modulator of vascular tone and blood pressure (BP), and experimental studies confirm an abnormal $\mathrm{NO}$ activity associated with essential hypertension. While an unequivocal pattern of endothelial NO-synthase (eNOS) inhibition in cardiovascular control has been recognized, the role of NO produced by neuronal nNOS remains unclear in normotensive as well as in hypertensive conditions. The aim of this study was to investigate and compare the effect of long-term administration of nNOS inhibitor 7-nitroindazole (7-NI) on arterial function and structure in normotensive and spontaneously hypertensive rats (SHR). Four groups of rats 10 weeks old were used: 1) Wistar, 2) Wistar administered 6 weeks daily 7-NI (10 mg/kg) in drinking water, 3) SHR, and 4) SHR treated with 7-NI same way. Systolic BP was measured using plethysmographic method. For functional study, the vasoactivity of isolated mesenteric artery (MA) was recorded. For morphological study, the geometry of MA was measured using light microscopy. Six-week treatment with 7-NI did not affect systolic BP in both experimental groups compared to the respective controls. The heart/body weight ratio in Wistar rats was decreased (cardiac hypotrophy) and it was increased (cardiac hypertrophy) in SHR after 7-NI administration. Relaxation of MA induced by acetylcholine was unchanged in both treated groups. Treatment with 7-NI in Wistar rats shifted the doseresponse curve to exogenous noradrenaline to the right so indicating the inhibition of MA contraction. On the other hand, administration of 7-NI augmented noradrenaline-inducecd contraction of MA in SHR. The contractile response induced by transmural nerve stimulation was increased in Wistar rats whereas it was unaffected in SHR after 7-NI treatment. The mass of MA wall in Wistar rats was decreased while the hypertrophy of the artery was observed in SHR after 7-NI administration.

The study revealed that nNOS participates in the regulation of the cardiovascular system (i) by other mechanisms than eNOS, and (ii) differently in normotensive and spontaneously hypertensive rats. The results suggest that chronic inhibition of nNOS, independently of the rat strain, did not change the systolic BP. On the other hand, it evoked different changes in vascular function and structure in Wistar rats and SHR suggesting that, in essential hypertension, NO released by the nNOS isoform triggers different regulatory pathways than in normotensive conditions.

Supported by VEGA2/0111/11, 2/0019/11, and SK-SRB-002609

\section{8 \\ Relevance of Baroreflex Sensitivity in Hypertensives After Ischemic Stroke \\ D. Čelovská \\ $2^{\text {nd }}$ Department of Internal Medicine, Faculty of Medicine, Comenius University, University Hospital, Bratislava, \\ Slovakia}

Objective: Impaired baroreflex sensitivity (BRS) is a noninvasive marker of autonomic dysfunction which has been observed in acute stroke and is associated with higher risk of long-term poststroke mortality and disability. The aim of the present study was to evaluate the clinical significance of baroreflex sensitivity in hypertensives 6 months and more after ischemic stroke onset. Design: A total of 26 hypertensive patients ( $66 \pm 10$ years of age, 11 females/15 males) with a history of first-ever ischemic stroke, which was neuroradiologically confirmed, were studied. These were compared to 30 hypertensive patients without a history of any cardiovascular event, being of similar age and sex. The relationship between BRS and blood pressure in hypertensives with stroke in comparison with a group of stroke-free control patients was evaluated. Method: BRS expressed in $\mathrm{ms} / \mathrm{mmHg}$ or in $\mathrm{Hz} / \mathrm{mmHg}$ (BRSf) was determined by the sequence and spectral methods: a five-minute non-invasive beat-to-beat recording of blood pressure and R-R interval with use of a Collin CBM7000 monitor, controlled breathing at a frequency of $0.1 \mathrm{~Hz}$. Results: A significant negative correlation between BRS and systolic blood pressure, and mean beat-to beat blood pressure was present $(\mathrm{p}<$ 0.001). BRS values obtained by the spectral method (BRS spect) and sequence method (BRS seq) in hypertensives with stroke were significantly lower even 6 months and more after stroke onset compared 
to stroke-free control patients (BRS spect $\mathrm{p}=0.0237$; BRS spect $\mathrm{p}=$ 0.0285 ; BRS seq $p=0.0532$; $B R S f$ seq $=0.0273$ ). The greatest decline in BRS values was in hypertensive stroke patients with metabolic syndrome, who had BRS values below $3 \mathrm{~ms} / \mathrm{mmHg}$. This finding was independent of age-dependent decrease of BRS. Conclusion: Examination of baroreflex sensitivity as a marker of autonomic dysfunction along with global cardiovascular risk stratification of poststroke hypertensives seems to be a method for identifying patients at high residual cardiovascular risk.

\section{9}

\section{Antioxidant Response and Radical Signaling in Different Experimental Models of Hypertension}

\author{
1. Dovinová1, M. Barančík², L. Gajdošechová3, R. Gardlik ${ }^{4}$ \\ ${ }^{1}$ Institute of Normal and Pathological Physiology, ${ }^{2}$ Institute \\ of Heart Research, ${ }^{3}$ Institute of Experimental \\ Endocrinology, Slovak Academy of Sciences, ${ }^{4}$ Institute of \\ Molecular Biomedicine, Faculty of Medicine, Comenius \\ University, Bratislava, Slovakia
}

Superoxide dismutase (SOD) plays an important role in cardiovascular tissues. Studies with inhibited extracellular SOD show that NO cannot be released from endothelium without oxidative degradation. In this way, SOD enzymes play an important role in vasodilatation and protection of $\mathrm{NO}$ in blood vessel walls, regulate oxidative damage and individual isoforms act as modulators of radical cell signaling influencing hypertrophy and/or proliferation of cardiovascular tissues. The present studies focused on the role of a free radical, superoxide, and subsequent activation of antioxidant response (SOD activity, total antioxidant status), oxidative damage, and ROS signaling during various experimental hypertension treatments and conditions. Application of DOX to young Wistar rats affected changes in blood pressure. We observed interplay between increase of blood pressure, level of superoxide, SOD activity, Akt kinase activation, and stimulation of metalloproteinase 2 of the rat heart. In young SHR, we found increased superoxide levels, oxidation of proteins; hovewer, SOD activities of the left ventricle and aorta were unchanged compared to young Wistar Kyoto rats. Short- and long-term transduction of SOD1 cDNA and or SOD2 cDNA improve blood pressure, changes in gene expression of selected genes, and decreased mitochondrial oxidative damage. The results indicate several connections between antioxidative response and/or oxidative damage in hypertension are triggered by free radicals and radical signaling.

Supported by SAS - NSC JRP 2010/01 and VEGA SR No 2/0205/09.

\section{0}

\section{Relationship Between BP Elevation in Exercise Tolerance Test and Night-to-Day BP Values During ABPM in Hypertensive Patients}

\author{
S. Filipová1,2, D. Škultétyová2 ${ }^{2}$. Chňupa ${ }^{2}$, A. Vachulová ${ }^{2}$ \\ ${ }^{1}$ Department of Cardiology, Faculty of Medicine, Slovak \\ Medical University, ${ }^{2}$ Department of Cardiology, National \\ Institute of Cardiovascular Diseases, Bratislava, Slovakia
}

Numerous studies have explained the predictive value of the day and night blood pressure (BP) difference by ambulatory BP monitoring (ABPM) for the evaluation of hypertension (HTN) control. During the exercise tolerance test (ETT), the rise of systolic BP is one of the signs for clinical hypertensive status. The objective of this study was to establish whether the baseline-to-peak BP value/ratio in ETT and night-to-day BP value/ratio in ABPM offers a better estimate of BP control in hypertensive patients. Methods: We analyzed BP values in the following situations: (1) physician's office measurement; (2) during ETT (treadmill test, Bruce protocol), and (3) during standard ABPM. All readings were performed in 3 groups: Group I - normotensive patients without coronary artery disease (CAD) $(n=34$; age 48.8 $\mathrm{SD} \pm 6.6 \mathrm{yrs}$, normal coronary angiography, office BP 126.2 $\pm 10.4 / 78.5 \pm 6.5 \mathrm{mmHg}$ ); Group II - hypertensive patients without $\mathrm{CAD}$ and with casual BP optimal control in physician's office $(\mathrm{n}=$ 32; age 52.4 $\mathrm{SD} \pm 5.7$; BP $129.5 \pm 8.1 / 80.2 \pm 8.7 \mathrm{mmHg}$ ); Group III - hypertensive patients without $\mathrm{CAD}$ and with casual office hypertensive BP values $(\mathrm{n}=40$; age 55.1 $\mathrm{SD} \pm 4.5$, BP $145.2 \pm 8.4 / 92.5 \pm 6.9$ $\mathrm{mmHg}$ ). Results: In uncontrolled HTN patients (Group III), compared with normotensives (Group I) during the ETT, the baseline-topeak systolic BP value differences were significantly higher $(58.8 \pm$ $9.5 \mathrm{mmHg}$ vs. $34.1 \pm 8.9 \mathrm{mmHg}$; $\mathrm{p}<0.005)$, but the total ETT time was shorter $(362.5 \pm 40.7 \mathrm{~s}$ vs. $547.2 \pm 65.5 \mathrm{~s} ; \mathrm{p}<0.001)$. In all groups, the night-to-day BP ratios were the highest in Group II, but the differences between patients' groups were not significant (Group I, $0.76 \pm 0.34$; Group II, $0.70 \pm 0.42$; Group III, $0.69 \pm 0.46$; n.s.). The night-to-day systolic BP values in ABPM were the highest in Group III vs. Group I; this difference was significant $(64.6 \pm 10.2 \mathrm{mmHg}$ vs. $39.8 \pm 11.7 \mathrm{mmHg} ; \mathrm{p}<0.001)$. The evaluated ETT parameters were significantly different between Groups II and III, but the ABPM parameters were not significantly different. Conclusions: According to our results: ETT has a significant informative value for the assessment of the BP control in hypertensive and normotensive patients, compared with ABPM. ETT may provide additional information vs. ABPM concerning the differentiation between well-controlled HTN and unsatisfactorily controlled HTN. 
11

\section{Expression of RAS Components in Epididymal and Retroperitoneal Adipose Tissues in Oxytocin-Induced Adipogenesis}

\author{
L. Gajdošechová, K. Kršková, D. Ježová, M. Eckertová, \\ M. Ondrejčáková, Š. Zorad
}

Institute of Experimental Endocrinology, Slovak Academy of Sciences, Bratislava, Slovakia

Our recently published data (Eckertova et al. 2011) show that oxytocin is a potent inducer of adipogenesis. In addition, the reninangiotensin system (RAS) is also implicated in the regulation of fat tissue mass (Janke et al. 2002, Zorad et al. 2006). Therefore, we investigated changes of local adipose tissue RAS in oxytocin-induced proliferated adipose tissue. Adult Wistar rats were treated by oxytocin $3.6 \mu \mathrm{g} / 100 \mathrm{~g}$ body weight/day for two weeks using osmotic minipumps. At the end of the treatment, the animals were sacrificed by decapitation. Epididymal (ET) and retroperitoneal (RT) adipose tissue was immediately removed, weighted and used for adipocyte size determination and/or kept frozen at $-70^{\circ} \mathrm{C}$ until analysis. Adipoctytes were isolated by collagenase digestion and their size was determined by light microscopy. Total RNA was isolated from 100 $\mathrm{mg}$ of frozen ET and RT adipose tissue using RNeasy Lipid Tissue Mini Kit (Qiagen, USA). Real-time PCR was performed using the RotorGene 2000 real-time cycler (Corbett Research, Sydney, Australia). Two-week oxytocin infusion increased the number of small adipocytes in ET without any change in the amount of the tissue. The increased adipogenesis in ET was accompanied with significantly increased expression of angiotensinogen, ACE, and a tendency to increase in AT1 receptor expression. In RT, the expression of angiotensinogen and AT1 receptor was not changed and the ACE expression was even decreasing. The increased expression of RAS components in proliferated adipose tissue in vivo is in line with the same results obtained in in vitro culture of differentiated preadipocytes (Janke et al. 2002). The absence of increased RAS component expression in RT is probably due to decreased sensitivity of this adipose tissue depot to oxytocin-induced adipogenesis. In ET, oxytocin treatment upregulated oxytocin receptors while no effect of oxytocin was seen in RT. Our results emphasize the role of RAS in adipose tissue development and point out to the differences between diverse fat tissue depots. 07

Supported by grants VEGA 2/0089/11 and SAS-NSC JRP 2010/
12

\section{Heart Rate and Blood Pressure in the General Croatian Population - EH-UH Study}

S. Karanović, D. Mrazovac, K. Kordić, T. Željković Vrki, I. Pećin, A. Jovanović, D. Podobnik, M. Laganović, B. Jelakovic

${ }^{1}$ School of Medicine University of Zagreb, Department of Nephrology, Arterial Hypertension and Dialysis, ${ }^{2}$ Outpatient Clinic Dugave, Zagreb, ${ }^{3}$ Outpatient Clinic Sv. Ivan, Zelina, Croatia

Introduction: The prognostic value of heart rate (HR) for the development of hypertension and as an important cardiovascular risk factor is still neglected. Until now, there is no data on HR and its correlation with blood pressure (BP) in the Croatian general population. Subjects and methods: Of 1,447 subjects enrolled in a nationwide survey (EH-UH study), 672 participants were eligible (302 men and 370 women) for further analyses (treated hypertensives and those with incomplete data were excluded). HR and BP were measured following ESH guidelines. The aim of the study was to determine HR values and analyse if there is a correlation between HR and BP in the general Croatian population. Results of this study show that men with high normal BP have a significantly higher HR than the men with optimal BP values $(74.5$; 95\% CI $67.3-79.8$ vs.72.2; 95\% CI $66.9-78.0 ; \mathrm{p}=0.032)$, but they do not differ from the hypertensives (74.5; 95\% CI 67.0-79.7; $p>0.05$ ). In women, there is a significant difference in HR values among all normal BP categories and the hypertensive group $(\mathrm{p}=0.003)$. HR is higher in men than in women appertaining to categories of optimal BP $(72.2 ; 95 \%$ CI $66.9-78.0$ vs.70.1; 95\% CI 66.5-73.6; $\mathrm{p}=0.067)$ and stage 1 hypertension $(\mathrm{p}=$ $0.016)$. Subjects in stage 3 hypertension group have the highest values of HR $(p=0.004)$. A significant correlation was observed between $\mathrm{HR}$ and systolic and diastolic BP in the whole group ( $\mathrm{r}=0.19 ; \mathrm{r}=0.21$, respectively; $p<0.001$ ) and in both genders. Conclusion: HR was higher in subjects with high normal than optimal BP, with the difference being more significant in men. In both genders, a statistically significant correlation between HR and BP was found. Our results confirmed previous studies showing that HR should be seriously considered from the beginning of the cardiorenal continuum. 


\section{3}

\section{Heart Rate, Insulin Resistance, Obesity and Blood Pressure in Croatian Rural Population}

\author{
S. Karanović, I. Vuković Lela, Ž. Dika, I. Pećin, A. Cvitković, \\ M. Bitunjac, M. Fuček, J. Kos, M. Abramović, D. Jurić, \\ J. Sertić, B. Jelaković \\ 'Department of Nephrology, Arterial Hypertension and \\ Dialysis, UHC Zagreb and School of Medicine University \\ of Zagreb, ${ }^{2}$ Laboratory for Clinical Diagnosis, General \\ Hospital Slavonski Brod, ${ }^{3}$ nstitute for Public Health \\ Brodsko Posavska County, Outpatient Clinic Bebrina, \\ Croatia
}

Aim: To investigate the relation of increased sympathetic tone (heart rate), insulin resistance, overweight and blood pressure (BP) in the general rural population. Design and Method: Of 1,289 subjects enrolled in a cross sectional survey, 272 participants (118 men, 154 women, median age 51 years, range 18-87) were included into this analysis. BP and heart rate (HR) were measured 3 times in the sitting position with an OMRON M6 device. Body mass index (BMI) and waist circumference (WC) were determined. Fasting blood glucose and insulin were determined. HOMA index was used to calculate insulin resistance (IR). Subjects were divided into three groups: normal BP $(<130 / 85 ; \mathrm{n}=113)(\mathrm{NBP})$, prehypertension $(130 / 85-$ $139 / 89 ; n=25)(\mathrm{PH})$, and untreated hypertension $(\geq 140 / 90 ; n=65)$ (HT). Kruskal-Wallis, Mann Whitney, and Spearman correlation tests were used. Significance was set at 0.05 . Results: There were no differences in age between the groups. An increasing trend in all of the measured variables was found among the 3 groups. Significant differences in BMI were observed between NBP vs. PHT and HT $(\mathrm{p}<$ 0.001); furthermore a significance was found in WC and HOMA index between NBP and HT. HR did not differ significantly between the three groups. Systolic and diastolic BP were found to significantly correlate with BMI, WC and HOMA index ( $<<0.0001 ; \mathrm{p}<0.004)$, but not with HR $(\mathrm{p}=0.667)$. However, HR correlated significantly with HOMA index $(\mathrm{r}=0.250 ; \mathrm{p}<0.0001)$. A significant correlation between HOMA index and BP was observed as well $(\mathrm{r}=0.225 ; \mathrm{p}=$ 0.0002 for systolic BP; $r=0.239 ; \mathrm{p}=0.0001$ for diastolic BP). Conclusion: BP is strongly related with BMI, WC and insulin resistance. A direct relation between $\mathrm{BP}, \mathrm{BMI}, \mathrm{WC}$ and sympathetic tone (HR) was not found, but a trend of increasing HR among the BP groups was observed. The positive correlation between HR and HOMA index might suggest on a common mechanism involved in both conditions. These preliminary results are encouraging.

\section{4 \\ Search for Optimal Interpretation of Blood Pressure in Childhood}

\section{E. Kellerová, V. Regecová}

Institute of Normal and Pathological Physiology, Slovak

Academy of Sciences, Bratislava, Slovakia

Continuing accumulation of evidence confirms rooting of hypertension (HY) already in childhood, and points out the importance of early preventive intervention. Incorporation of blood pressure (BP) measurement in the standard pediatric examination is a must. However, satisfactory reference data with which to interpret the clinical meaning of BP readings in children of different age in everyday practice are lacking. The recent guidelines (ESH 2009) provide standards for BP classification in children, reproducing NHBPEP (2004) tables based on a large US population survey. This study is an attempt to demonstrate that a distributional analysis of a general population, no matter how extensive, is not an appropriate normative basis for establishing normal, age-related BP values in healthy children, as it includes a significant proportion of subjects with HY, elevated BP or overweight and obesity. ESH criteria were applied on a database pooling existing data on BP and somatometric parameters in children, collected by several working groups in different regions of Slovakia, and consisting of 5,510 boys and 5,607 girls aged 3-17 years. The presentation considers the systolic BP only. The resulting BP values at each age would depend on the overweight prevalence in each group and on the proportion of BP readings exceeding $120 \mathrm{mmHg}$. In the presented survey, the percentual rate of obesity represented $6-25 \%$ in boys and $9-21 \%$ in girls aged 3-17 yrs, mainly at the age of pubescence. At school age, overweight increased the incidence of systolic $\mathrm{BP}>120 \mathrm{mmHg}$ in different age groups by $2-11 \%$, the average BP systolic values by $5-11$, and the $90 \mathrm{P}$ by $5-17 \mathrm{mmHg}$. On the other hand, its contribution to the $\mathrm{BP}$ distribution in preschool children was negligible. The proportion of systolic BP values $>120 \mathrm{mmHg}$ increased continually with age from about $2 \%$ at 3 yrs., reaching a plateau of $30-40 \%$ in girls at the age of 12 yrs., but continuing up to $60-65 \%$ in boys from the age of 15 yrs. Nevertheless, for preschooland younger school age, this limit is disproportionate and has to be lower. The results of several different analytic strategies to determine the range and percentil distribution of normal age-related BP, based on the modified database of children and adolescents of Slovakia, will be presented as an attempt to answer the often asked question "Which levels of BP in childhood are normal?"

Supported by grants APVV-0523-10, VEGA-2/0084/10, and by a scientific grant of the Slovak Society of Cardiology.

15

\section{Symmetric Dimethyl-L-Arginine Level Is Positively Correlated with Carotid-Femoral Pulse Wave Velocity in Hypertensive Subjects}

L. Klima' ${ }^{1}$, K. Stolarz-Skrzypek1, J. Menne ${ }^{2}$, A. Olszanecka1, W. Wojciechowska1', G. Bilo ${ }^{3}$, K. Kawecka-Jaszcz ${ }^{1}$

${ }^{1}$ First Department of Cardiology and Hypertension, Jagiellonian University Medical College, Krakow, Poland,

${ }^{2}$ Klinik für Nieren- und Hochdruckerkrankungen, Hannover, Germany, ${ }^{3}$ Department of Cardiology, Istituto Auxologico Italiano, Milan, Italy

Objective: Oxidative stress raises a considerable interest in the pathophysiology of cardiovascular disease. The objective of the study was to evaluate oxidative stress markers [dimethylated L-arginine (ADMA), symmetric dimethyl-L-arginine (SDMA), oxidized low density lipoproteins (ox-LDL), and advanced oxidation protein products (AOPPs)] in essential hypertension and to search for possible 
relations between oxidative stress markers and arterial stiffness. Design and Methods: We recruited 50 families of hypertensive subjects followed at the Outpatient Hypertension Clinic (index person with at least 3 first-degree relatives, at least one hypertensive relative). For the current analysis, we included 185 subjects; M/F $89 / 96$. Blood pressure was measured with a validated oscillometric device, on two separate occasions ( 2 x 3 consecutive measurements). Hypertension was defined as use of antihypertensive drugs and/or blood pressure $\geq 140 / 90 \mathrm{mmHg}$. In every subject, carotid-femoral pulse wave velocity (PWV) was measured with a Sphygmocor device. For the measurement of oxidative stress markers, we collected fasting blood samples in the morning. Results: The study group included 130 hypertensive and 55 normotensive subjects. Hypertensive and normotensive subjects differed in terms of age, blood pressure, and PWV ( $48 \pm 15$ vs. $34 \pm 12$ years; $p<0.0001 ; 141 \pm 22 / 84 \pm 12$ vs. 126 $\pm 13 / 78 \pm 9$ mmHg; $p<0.0001$ for both; $871 \pm 210$ vs. $738 \pm 155$ $\mathrm{cm} / \mathrm{s}$, respectively; $\mathrm{p}<0.0001)$. We found a significant positive correlation between SDMA and age $(r=0.20 ; p=0.005)$, BMI and AOPP $(\mathrm{r}=0.15 ; \mathrm{p}=0.043)$ and a negative correlation in the normotensive group between oxLDL and age $(r=-0.3 ; \mathrm{p}=0.039)$. We did not find any relationship between gender and smoking status with oxidative stress markers. In general linear model analysis, we did not observe any association between oxidative stress markers and hypertension (ADMA: 0.57 vs. $0.58 ; \mathrm{p}=0.89$; SDMA: 0.72 vs. 0.70 ; $\mathrm{p}=0.42$; oxLDL: 390.81 vs. $335.55 ; \mathrm{p}=0.57$; AOPPs: 53.66 vs. 50.50; $\mathrm{p}=0.77$ ). There was a significant positive correlation between SDMA and PWV for both hypertensives $(\mathrm{r}=0.19 ; \mathrm{p}=0.031)$ and the whole study cohort $(r=0.20 ; p=0.006)$. Conclusion: The observed significant positive association between SDMA and pulse wave velocity in both hypertensive subjects and whole cohort might suggest a role of oxidative stress in the pathogenesis of arterial stiffness.

18

Metabolic Parameters After the Replacement of ACE Inhibitors by the AT1 Receptor Blocker Candesartan in Hypertensive Patients

\author{
K. Kršková', A. Okša ${ }^{1}$, R. Imrich ${ }^{2}$, Š. Zorad ${ }^{2}$ \\ ${ }^{1}$ Slovak Medical University, ${ }^{2}$ Institute of Experimental \\ Endocrinology, Slovak Academy of Sciences, Bratislava, \\ Slovakia
}

In addition to the antihypertensive effect of candesartan [angiotensin II receptor type 1 blocker (ARB)], this drug has been postulated to improve insulin sensitivity, attenuate inflammation, lower fat tissue mass, and reduce adipocyte size [Zorad et al. 2006; Koh et al. 2006; Higashiura et al. 1999]. In the present pilot study, we investigated the effect of candesartan cilexetil therapy on changes in adiposity and glucose metabolism in subjects with primary hypertension. Fourteen men (between 33-64 years of age) with primary hypertension (European Society of Hypertension/European Society of Cardiology Grade 1,2) treated with angiotensin-converting enzyme inhibitors (ACEI) participated in the study. ACEI therapy was replaced by candesartan for 6 months while any other additional antihypertensive medication remained unchanged. Experimental procedures were performed before and after the replacement of hypertension treatment and involved anthropometric measurements, blood pressure and heart rate measurements, the oral glucose tolerance test, and adipocyte size measurements. Six months after ACEI replacement by candesartan, the systolic and diastolic blood pressure was lower $(\mathrm{p}<$ 0.05) compared to pre-change values; systolic blood pressure decreased by $6.95 \pm 4.07 \mathrm{mmHg}$ and diastolic blood pressure decreased by $5.68 \pm 2.35 \mathrm{mmHg}$. Fasting glycemia was lower $(\mathrm{p}<$ 0.01 ) after candesartan therapy since the mean fasting plasma glucose decreased by $0.84 \pm 0.06 \mathrm{mmol} / \mathrm{L}$. Insulin sensitivity index [Matsuda et al. 1999] tended to increase $(\mathrm{p}=0.08)$. Changes in all other analysed characteristics were not found to be statistically significant. As expected, our results showed that candesartan cilexetil had blood pressure-lowering effects, which were comparable to those of ACEI. This result is in line with other larger studies comparing ACEI or ARB efficiency in primary hypertension treatment. Although the change from ACEI to candesartan resulted in lowering of fasting plasma glucose, we did not observe other signs of improvement in insulin sensitivity. This study is continuing by increasing the number of examined patient and analyzing changes in adipokine expression.

Supported by grant of Slovak Ministry of Health MZ2007/27SAV-02.

20

\section{Endocrine and Metabolic Changes in Early Stage of Hypertension}

\author{
A. Penesová1, E. Čižmárová , Ž. Rádiková1, M. Vlček', \\ R. Imrich ${ }^{1}$ \\ ${ }^{1}$ Institute of Experimental Endocrinology, Slovak Academy \\ of Sciences, ${ }^{2}$ Outpatient Cardiologic Department for \\ Children and Youth, Bratislava, Slovakia
}

The early stage of hypertension onset is associated with an enhanced sympathetic tone, which may negatively influence the endocrine response to different stimuli. Therefore, the aim of our study was to determine the response of catecholamines, pituitary hormones, cortisol, plasma renin activity, and aldosterone to insulininduced hypoglycemia in patients with juvenile hypertension (HT). The second aim was to estimate the relationship between the neuroendocrine response to stress stimulus and metabolic parameters in those patients and in healthy controls (NT). Methods: Insulin tolerance test (ITT; $0.1 \mathrm{IU}$ actrapid/kg of body weight i.v.) and oGTT were performed in 21 HT male subjects and in 19 NT males. Concentrations of growth hormone $(\mathrm{GH})$, prolactin (PRL), ACTH, cortisol, catecholamines, plasma renin activity (PRA), glucose, insulin, and lipid profile were determined in venous plasma. Insulin resistance index (IR) HOMA2 and indices of insulin sensitivity (ISI) were calculated. Results: Increased baseline levels of norepinephrine $(p<0.05)$, increased response of norepinephrine $(p<0.001)$ and decreased response of GH $(\mathrm{p}<0.001)$, PRL $(\mathrm{p}<0.001)$, ACTH $(\mathrm{p}<0.05)$ and cortisol $(\mathrm{p}<0.001)$ to hypoglycemia were found in hypertensive patients when compared to normotensive controls. Hypertensive patients had a higher 2-hour plasma glucose concentration $(\mathrm{p}=0.01)$, still within the range of normal glucose tolerance, and lower insulin sensitivity indices $(p=0.001)$. Conclusions: The early stage of onset of hypertension (in normal weight and young patients) is associated with sympathetic overactivity and a decreased pituitary 
response to metabolic stress stimulus. These changes may also contribute to metabolic cardiovascular risk factors.

\section{1}

\section{Arterial Hypertension, Atrial Fibrillation and NT-proBNP}

V. Pokorná, J. Kalužay, O. Jurkovičová, P. Pontúch

$4^{\text {th }}$ Department of Internal Medicine, Faculty of Medicine, Comenius University, St. Cyril and Methodius University

Hospital, Bratislava, Slovakia

Introduction: Arterial hypertension (AH) is one of the main risk factors of atrial fibrillation (AF). Left ventricular (LV) hypertrophy significantly influences atrial function in hypertensive patients. NT-proBNP values correlate with left ventricular mass index (LVMI) and are significantly increased in concentric LV hypertrophy. Patients with AF show a significant NT-proBNP elevation even in the absence of heart failure and a decrease after successful cardioversion. Aims: The aims of this study were to 1) establish correlation between LVMI and NT-proBNP in patients with AF, 2) determine the values of LVMI and NT-proBNP as predictors of AF recurrence following successful cardioversion, 3) determine the correlation between NT-proBNP and type of LV geometry. Methods: Twenty-nine patients [24 (83\%) with $\mathrm{AH}$ ] without a history of heart failure and with persistent or paroxysmal AF undergoing cardioversion (electrical, pharmacological or spontaneous) were included. NT-proBNP was measured before (NT-proBNP1) and at least 48 hours post-cardioversion (NT-proBNP2). At a follow-up at least 4 weeks after cardioversion, a third sample of NT-proBNP (NT-proBNP3) was obtained together with continuous 24-hour ECG monitoring. Patients were divided into 2 groups according to the result of continuous 24-hour ECG monitoring; with group A comprising patients with sinus rhythm (14 individuals) and group B consisting of patients with paroxysms of AF ( 9 individuals). The type of LV geometry was determined using the LVMI and relative wall thickness. Results: Independent predictors of AF recurrence determined by multivariate regression analyses were $\mathrm{AH}$, female gender and NT-proBNP3, but not LVMI or left atrial (LA) diameter. The most frequent type of LV geometry was concentric remodelling with the lowest NT-proBNP levels in comparison to other types of LV geometry. There was no significant difference in LVMI between group A [93 (82-108) g/ $\mathrm{m}^{2}$; median (interquartile range)] and group B [101 (97-145) g/m²]. The baseline NT-proBNP1 levels showed no significant difference between group A [866 (235-1935) ng/l] and group B [1384 (809-2129) ng/l]. However, the NT-proBNP2 and NTproBNP3 were significantly lower in group A than in group B [120 (55-456) ng/l vs. 449 (213-1081) ng/l; 83 (26-233) ng/l vs. 576 $(186-871) \mathrm{ng} / \mathrm{l})(\mathrm{p}<0.05)]$. All three NT-proBNP samples correlated with LVMI; NT-proBNP was increasing with increasing LVMI $(\mathrm{p}<$ $0.05)$. LA diameter showed a positive correlation with LVMI $(\mathrm{p}<$ 0.01 ). Conclusion: Our study showed a correlation between LVMI, type of LV geometry and NT-proBNP levels in patients with AF and determined AH, female gender and NT-proBNP3 as independent predictors of AF recurrence.
22

\section{Nitric Oxide Is Not the Cause of Endothelial Dysfunction in Femoral Arteries in an Experimental Model of Human Prehypertension}

\author{
A. Púzserová1, J. Kopincová2, P. Slezák1 , I. Bernatová ${ }^{1}$ \\ ${ }^{1}$ Institute of Normal and Pathological Physiology, Centre of \\ Excellence for Cardiovascular Research, Slovak Academy \\ of Sciences, Bratislava, ${ }^{2}$ Department of Physiology, \\ Jesenius Faculty of Medicine, Comenius University, \\ Martin, Slovakia
}

Chronic hypertension is generally considered to be a risk factor of several cardiovascular diseases. On the other hand, relatively little attention has been paid to prevention of cardiovascular risk resulting from marginal elevation of blood pressure (BP). The borderline hypertensive rat (BHR) is an experimental model of human prehypertension and early stage hypertension. This study examined nitric oxide (NO) production, oxidative load and seriousness of cardiovascular alterations in adult male 22-week-old BHR as compared to spontaneously hypertensive (SHR, positive control) and normotensive Wistar-Kyoto (WKY, negative control) rats. Blood pressure (BP) was determined by tail-cuff method. NO production was determined by conversion of [3H]-L-arginine in the aorta and left ventricle (LV). Conjugated dienes (CD) and concentrations of thiobarbituric acidreactive substances (TBARS) were measured in the LV and kidney (for assessment of oxidative load). Vascular function was investigated in rings of the femoral artery (FA) using a wire myograph. BP of WKY, BHR and SHR was 106.2, 143.3 and $191.3 \mathrm{mmHg}$, respectively ( $p<0.01$ for each). Significant LV hypertrophy was present in BHR and SHR. NO production was elevated significantly in the aorta of BHR and SHR vs. WKY and in the LV of SHR vs. WKY. Oxidative stress markers were increased in the LV and kidney of BHR and SHR vs. WKY. Endothelium-dependent relaxation induced by acetylcholine (ACh) of the FA was reduced in both BHR and SHR vs. WKY; however, endothelial dysfunction was more pronounced in SHR. The $\mathrm{NO}$-dependent component of ACh-induced relaxation was similar in all groups investigated. However, the NO-independent component of ACh-induced relaxation was reduced significantly in BHR and SHR vs. WKY. Moreover, a negative correlation $(r=-0.66, p<0.0004)$ was observed between NO-independent relaxation and BP. ACh at higher concentrations caused endothelium-dependent contractions in BHR and SHR FA, but not in FA from WKY. In conclusion, the data showed that LV hypertrophy and NO-independent endothelial dysfunction were present already in BHR. Thus the results suggest that borderline hypertension represents a risk of other cardiovascular diseases which is qualitatively similar to that of fully developed hypertension.

Supported by the Slovak Grant Agency for Science, grant No. 2/0084/10 and APVV-0523-10. 


\section{3}

\section{Young and Old Hypertensive Rats Benefit from Omega-3 Fatty Acids Diet due to Attenuation of Myocardial Abnormalities in Intercellular Signaling and Suppression of Malignant Arrhythmias}

\author{
J. Radošinská1,2, B. Bačová2, T. Beňová2, V. Knezl', \\ J. Slezák², N. Tribulová ${ }^{2}$ \\ ${ }^{1}$ Institute of Physiology, Faculty of Medicine, Comenius \\ University, ${ }^{2}$ Institute for Heart Research, Slovak Academy \\ of Sciences, Bratislava, Slovakia
}

Background and Purpose: Hypertension-induced myocardial remodeling is known to be associated with increased propensity to malignant arrhythmias and sudden death partially due to alterations in cell-to-cell coupling protein, connexin-43 (Cx43). We investigated whether omega- 3 fatty acids diet can protect from malignant arrhythmias via modulation of intercellular $\mathrm{Cx} 43$-mediated signaling and intracellular signaling mediated by protein kinase C (PKC) at early and late stages of structural remodeling. Design and Methods: Untreated male 3- and 12-month-old spontaneously hypertensive rats (SHR) and age-matched healthy Wistar rats were compared with animals supplemented by omega-3 FA (EPA+DHA $30 \mathrm{mg} /$ day) for two months. Body weight, blood pressure, glucose and plasma lipids profile were monitored. Left ventricular tissues were taken for immunoblotting of $\mathrm{Cx} 43$ and PKC-isoforms. Langendorff-heart preparation was used to test VF inducibility. Key results: Immunobloting of all rat hearts revealed conventional patterns of $\mathrm{Cx} 43$ expression, i.e. two phosphorylated forms $\mathrm{Cx} 43$ (P-Cx43) that are needed for the function of $\mathrm{Cx} 43$ channels, and one non-phosphorylated (noP-Cx43) form. Neither total Cx43 expression nor P-Cx43 was significantly altered in young unlike old SHR heart, which exhibited a marked decrease of both parameters. However, the ratio of $\mathrm{P}-\mathrm{Cx} 43$ to total $\mathrm{Cx} 43$ was significantly reduced in young SHR hearts and markedly increased due to omega-3 FA diet in all SHR. In addition, omega-3 FA diet significantly enhanced total $\mathrm{Cx} 43$ expression as well as P-Cx43 in old SHR. Expression of PKC-epsilon, which phosphorylates Cx43, was significantly decreased in both young and old SHR, while augmented due to omega-3 FA diet. On the other hand, the expression of PKC-delta (which promotes fibrosis) was increased in the hearts of SHR and suppressed by the treatment. Furthermore, omega-3 FA diet significantly reduced the incidence of electrically-inducible VF in both young and old SHR. Conclusions and Clinical Implication: Results indicate that both young and old hypertensive rats benefit from omega-3 fatty acids diet due to alleviation of myocardial abnormalities in connexin-43 and protein kinase-C signaling associated with suppression of malignant arrhythmias. It appears that omega-3 fatty acids might be included in the management of patient suffering from hypertension.

\section{4}

\section{Trends in Incidence of Obesity and of Higher Blood Pressure Values in Children at 10 Years of Age in Different Regions of Slovakia}

\author{
V. Regecová1, E. Kellerová1, P. Šimurka², J. Bérešová3 \\ ${ }^{1}$ Institute of Normal and Pathological Physiology, Slovak \\ Academy of Sciences, Bratislava, ${ }^{2}$ Department of \\ Pediatrics, Teaching Hospital, Trenčín, ${ }^{3}$ Regional Office of \\ Public Health, Rimavská Sobota, Slovakia
}

Aim: The transversal study was aimed to compare the incidence of high blood pressure (BP) values in children 10 years of age in relation to the incidence of obesity and places of their residence in Slovakia after a decade between 2001 and 2010. Methods: The first data set, 2001, of BP and basic anthropometric parameters $(n=5,410)$ was collected at the preventive health examinations by the outpatient units for children and adolescents. The recent measurements, 2010 (n $=1,353$ ), were performed by health specialists at schools. BP was measured by mercury sphygmomanometry using appropriate cuff dimensions and in line with the ESH recommendations. For comparison of anthropometric parameters, the Slovak anthropometrical survey (2001) was used as reference. Obesity was evaluated by comparison to BMI-for-age reference data from 1990 [Vignerova et al., 2006]. To compare the incidence of prehypertension and hypertension after the decade, the cut-off value for normal BP was set at 119/79 $\mathrm{mmHg}$ according to ESH (2009). To assess the differences in the absolute BP values, the BP-for-height was used. For the two-sample comparison of the investigated indicators between original and recent survey, between boys and girls, different regions of Slovakia, and urban and rural residences, the two-way analysis of variance ANOVA was used. The differences in the incidence of obesity and hypertension were statistically evaluated by the chi-square test. Results: Between 2001 and 2010, there was no difference in the average values of body height in children 10 years of age. However, the disparity in height-for-age between the urban and rural populations became more evident in 2010. Mean BMI as well as the prevalence of overweight and obesity increased significantly $(p<0.01)$, mainly in girls from rural communities. The 2010 systolic BP-forheight values were on the average significantly higher $(p<0.001)$, not only in the obese, but also in those with normal body weight. The greatest increments in average systolic BP were observed in rural regions of Central Slovakia, and less, but still significant in the Eastern part and in Bratislava. During this decade, the diastolic BP did not change. The incidence of prehypertension and hypertension increased by a total of $9 \%$, but surprisingly more in children from rural regions (from $15.5 \%$ in 2001 to $28 \%$ in 2010). While, in 2001, the proportion of children with high systolic BP values was greater in the urban population $(\mathrm{OR}=0.96)$, it was greater in rural regions in $2010(\mathrm{OR}=1.08)$. Conclusions: Between 2001 and 2010, the incidence of overweight, obesity, and high systolic BP values significantly increased in children at the age of starting puberty, in particular in rural communities. This trend is not obviously attending the growth acceleration or unhealthy weights.

Supported by the Grant of Slovak Society of Cardiology, APVV0523-10 and VEGA-2/0084/10. 
25

\section{Blood Pressure in Teenagers in Some EU Countries and in USA - Comparative Study}

\author{
V. Regecová1, E. Kellerová1, A. Baráková², P. Šimurka³, \\ E. Čižmárová ${ }^{4}$ A. Jurko Jr. ${ }^{5}$, E. Ondrisková6 \\ ${ }^{1}$ Institute of Normal and Pathological Physiology, Slovak \\ Academy of Sciences, ${ }^{2}$ National Health Information Center, \\ Bratislava, ${ }^{3}$ Department of Pediatrics, Teaching Hospital, \\ Trenčín, ${ }^{4}$ Cardiology Outpatient Department for Children \\ and Youth, Bratislava, ${ }^{5}$ Department of Pediatrics, Jesenius \\ Faculty of Medicine, Comenius University, Martin, ${ }^{6}$ Pediatric \\ Cardiology Outpatient Department, Myjava, Slovakia
}

The aim of the study was to compare the age- and growth-related blood pressure values (BP) in children and adolescents of Slovakia with BP of their peers living in similar (Visegrad 4) or rather different geographic and social conditions. Methods: The study includes published representative data on $\mathrm{BP}$ and somatometric parameters in children and adolescents in the age range 11-17 years, collected during the last 10 years (y) in four neighbouring countries of Central Europe: Slovakia (SK), Czech Republic (CZ), Poland (PL), Hungary (HU), in some more distant ones: Italy (IT), England (EN), and data pooled in NHBEP (USA). All of the surveys were declared as "National reference BP data". In most of them including the Slovak one, BP was measured sphygmomanometrically, except in HU and EN, where validated oscillometric automatic devices were used. The Slovak survey included 2,933 boys (B) and 2,961 girls (G) aged 11-19 years (y) from all regions. Descriptive statistics was used for computation of mean values and variances of all investigated parameters. Significance of the differences in BP among peers of different countries was determined by unpaired $t$-tests. Results: Differences in body height-forage between the surveys reached up to $8 \mathrm{~cm}$. The highest values were found in SK and CZ boys $(p<0.001)$ as well as CZ girls $(p<0.001)$, notably at the age of 15-17 y. Mean values of BP in SK boys were almost equal to those in $\mathrm{CZ}$, except of somewhat lower systolic BP in the groups of 11 and $17 \mathrm{y}$. On the other hand, over the age of $14 \mathrm{y}$, the age-related systolic BP in the SK girls remained stable on the average at $113 \mathrm{mmHg}$ while, in $\mathrm{CZ}$ girls, its increase continued to up to 122 $\mathrm{mmHg}$. The trends and values of diastolic BP in the SK and $\mathrm{CZ}$ groups in both genders were alike. In general, the age-related systolic $\mathrm{BP}$ increment was greater at the ages between 11 and $15 \mathrm{y}$ than during the following period ranging, in boys, from $7 \mathrm{mmHg}$ (CZ, USA) to 10 $\mathrm{mmHg}$ (SK, HU, PL) and, in girls, from 2-3 mmHg (EN, SK, IT, USA) to $6 \mathrm{mmHg}$ (CZ, PL, HU). The period of the steepest agerelated BP rise in boys varied by countries: SK and IT (11-12 y), CZ, HU, and EN (12-13 y), PL (13-14 y). In girls of some countries (SK, IT, PL), the pubertal BP rise between 11 and $14 \mathrm{y}$ was followed by a slight decrease thereafter. In all surveys, significantly higher BP values were found in B older than 14 y compared to $\mathrm{G}$. The age-related rise of diastolic BP was more regular - about $0.5-3 \mathrm{mmHg}$ per year. Irrespective of age and sex, BP values in EU teenagers were significantly higher as compared to USA. Conclusions: The level and trend of the age-related BP development during juvenescence is rather variable in EU countries. The average BP values in both Slovak and Czech teenagers were the highest in Central Europe, with the lowest published (within the EU) being in Italy. The BP development is characterized by a steeper increase at the beginning of puberty. Despite major variability in the body height-for-age among the peers of dif-

6th Central European Meeting on

Hypertension 2011 ferent countries, the BP characteristics cannot be attributed only to this somatic parameter.

Supported by the Grant of Slovak Society of Cardiology, APVV0523-10 and VEGA-2/0084/10.

\section{6 \\ Essential Fatty Acid Levels in Plasma and Red Blood Cells of Untreated and Omega-3 Fatty Acid-Treated Male and Female Spontaneously Hypertensive Rats}

\author{
P. Sečn, B. Bačová2, M. Čertík ${ }^{1}$, N. Tribulová2
}

${ }^{1}$ Slovak University of Technology, ${ }^{2}$ Institute for Heart

Research, Slovak Academy of Sciences, Bratislava,

Slovakia

Background and Purpose: Omega-3 fatty acids (omega-3) are important components of cell membranes affecting their function as they are incorporated into phospholipids. Dietary deprivation of the essential fatty acids (FAs) is deleterious to health. Data from clinical and experimental studies support the hypothesis that increased consumption of omega-3 lowers the risk of cardiovascular disease (CVD) and sudden cardiac death. Hypertension is one of the main risk factors for CVD, and we have shown previously that hypertensive rats benefit from omega-3 intake. The aim of this study was to examine plasma (PL) and red blood cells (RBC) levels of essential FAs in old male and female spontaneously hypertensive rats (SHR) as well as non-hypertensive Wistar rats (WR) fed with omega-3 (Vesteralens, Norway, EPA+DHA $200 \mathrm{mg} /$ day/2 months) and compared with untreated rats. Methods: Blood PL and RBC were collected at the end of experiment and stored frozen until use. Total lipids were extracted into chloroform solution followed by chloroform evaporation in vacuum. As the next step, the samples were used for preparing FA methyl esters, which were assayed on a GC-6890 N gas chromatograph (Agilent Technologies). Recordings were evaluated using a ChemStation B0103 (Agilent Technologies) and quantified using C-4-C24 FA standards. The level of each omega-3: ALA (alfa linolenic acid), EPA (eicosapentanoic acid), and DHA (docosahexanoic acid), and omega-6 FA: LA (linoleic acid), AA (arachidonic acid), and GLA (gama linolenic acid) was expressed in a percentage of total free FA. Key results: In general, the levels of the assayed FAs were lower in PL than RBC. Compared to WR, the levels of FA in RBC of male SHR (with the exception of AA) were lower, while being higher in female SHR (with the exception of AA). Omega-3 intake in males resulted in an apparent increase of RBC levels of ALA, EPA, DHA and GLA, while a decrease of AA in WR as well as markedly suppressed elevated AA in SHR. Similar to males, omega-3 intake in females resulted in an increase of the RBC levels of ALA, EPA, DHA, and GLA, while a decrease of AA in WR. In addition, it caused a marked increase of the EPA level in SHR, while not affecting, compared to untreated female SHR, their high DHA and low AA levels. Conclusions: Results showed that there are sex-related differences in red blood cells levels of omega- 3 as well as omega-6 FA and that omega- 3 intake affects the red blood cells FA profile to benefit from higher anti-inflammatory omega-3 and lower pro-inflammatory omega-6 FA.

Supported by VEGA and APVV grants 2/0049/09, SK-UA-002209.

Kidney Blood Press Res 2011;35:89-105 
28

\section{Gender- and Age-Related Efficacy of Atorvastatin on Vascular Endothelial Function Demonstrated in Rats Suffering from Hypertriglyceridemia and Hypertension}

\author{
R. Sotníková1, B. Bačová2, J. VIkovičová, J. Navarová1, \\ N. Tribulová ${ }^{2}$ \\ ${ }^{1}$ Institute of Experimental Pharmacology and Toxicology, \\ ${ }^{2}$ Institute for Heart Research, Slovak Academy of \\ Sciences, Bratislava, Slovakia
}

Hypertriglyceridemia is an independent risk factor for coronary artery disease and participates in the development of atherosclerosis and hypertension in humans. Statins are the most widely prescribed drugs in the treatment of dyslipidemia. However, data about the efficacy of statins in relation to age and gender are lacking. The aim of the study was to compare the effect of atorvastatin (ATO) on endothelium-dependent relaxation of the superior mesenteric artery (SMA) of male vs. female rats as well in as young (5-mth-old) vs. old (13-mthold) HTG rats. Methods: ATO was administered p.o. for two months at a dose of $0.15 \mathrm{mg} / 100 \mathrm{~g} /$ day (young rats) or $0.30 \mathrm{mg} / 100 \mathrm{~g} /$ day (old rats). Control rats $(\mathrm{C})$ received a vehiculum. At the end of the experiment, blood pressure, body weight and plasma lipids were recorded and endothelial function of SMA was tested in vitro under isometric conditions. We evaluated the response of phenylephrine-precontracted rings to acetylcholine (ACh) before and after NO synthase inhibition with NG-nitro-L-arginine methyl ester (NO-resistant relaxation). Results: We found that endothelium-dependent relaxation was greater in young female than in male SMA. However, in old animals, the relaxation response of SMAs to Ach was more pronounced in males than females. While the responses of SMA to ACh of old male rats were not statistically different compared to young rats, responses of old female rats were much less than those of young ones. Administration of ATO resulted not only in an improvement of the lipid profile of HTG rats, it also improved endothelium-dependent relaxation of animals. The most pronounced enhancement of Ach relaxation after ATO treatment was noted in old female rats. NO-resistent relaxation was not influenced either by gender and age of animals, or by treatment. In conclusion, our results showed the influence of age and gender on endothelial function of SMA of HTG rats. It appears that the worse endothelial function, the more effective ATO treatment.

Supported by VEGA grants No. 2/0086/08 and 2/0049/09.

\section{0}

Longitudinal Changes in Blood Pressure in Relation to 5 Candidate Genes and Urinary Sodium Excretion in 1405 Subjects from 5 European Populations

\author{
K. Stolarz-Skrzypek', T. Kuznetsova ${ }^{2}$, L. Thijs' ${ }^{2}$, \\ W. Wojciechowska', V. Tikhonoff ${ }^{3}, J$. Seidlerova", \\ E. Brand ${ }^{5}$, G. Bianchi, S. Malyutina ${ }^{7}$, E. Casiglia ${ }^{3}$, \\ J. Filipovsky ${ }^{4}$, K. Kawecka-Jaszcz'1 Y. Nikitin7, J. Staessen ${ }^{8}$
}

${ }^{1}$ First Department of Cardiology and Hypertension, Jagiellonian University Medical College, Kopernika, Krakow, Poland, ${ }^{2}$ Studies Coordinating Centre, Division of Hypertension and Cardiovascular Rehabilitation,

Depatment of Cardiovascular Disease, University of Leuven, Leuven, Belgium, ${ }^{3}$ Department of Clinical and Experimental Medicine, University of Padova, Padova, Italy, ${ }^{4}$ Internal Department II, Faculty of Medicine, Charles University, Pilsen, Czech Republic, ${ }^{5}$ Department of Internal Medicine D, Nephrology and Hypertension, University of Munster, Munster, Germany, ${ }^{6}$ Division of Nephrology and Dialysis, Chair of Nephrology, San Raffaele Scientific Institute, Università "Vita-Salute”, San Raffaele Hospital, Milan, Italy, ${ }^{7}$ Institute of Internal Medicine, Novosibirsk, Russian Federation, ${ }^{8}$ Department of Epidemiology, Maastricht University, Maastricht, Netherlands

Objective: The genes encoding angiotensin converting enzyme (ACE), adducin subunits (ADD1, ADD2 and ADD3) and aldosterone synthase (CYP11B2) share the potential of influencing blood pressure (BP) via sodium homeostasis. In this analysis, we aimed to investigate longitudinal changes in $\mathrm{BP}$ in relation to polymorphisms in the aforementioned genes (ACE I/D, ADD1 Gly460Trp, ADD2 C1797T, ADD3 A386G, and CYP11B2 C-344T) in white Europeans recruited from 5 populations. Design and Methods: At baseline and after median (IQR) 6.3 (5.2-8.3) years of follow-up, we measured conventional BP and 24-h urinary sodium excretion (24-h UVNa) as index of salt intake, in 1,405 never treated subjects recruited using a family-based random sampling frame from Hechtel-Eksel (Belgium, $\mathrm{n}=1038$ ), Kraków (Poland, $\mathrm{n}=106$ ), Novosibirsk (Russian Federation, $\mathrm{n}=64$ ), Padova (Italy, $\mathrm{n}=138$ ) and Pilsen (Czech Republic, $n=59$ ). The analyses of genotype-phenotype relations were adjusted for covariables and relatedness of study participants. Results: In analyses not accounting for urinary sodium, ACE DD homozygosity was associated with a greater increase in diastolic BP during follow-up (DD vs. DI+II (adjusted mean \pm SE): $5.40 \pm 0.50$ vs. $4.40 \pm 0.39 \mathrm{mmHg} ; \mathrm{p}=0.036)$, but not in systolic BP $(5.72 \pm 0.69 \mathrm{vs}$. $4.72 \pm 0.54 \mathrm{mmHg} ; \mathrm{p}=0.14)$ as compared to I-allele carriers. We have not observed any association between polymorphisms in CYP11B2 and 3 adducin subunits and follow-up changes in blood pressure. The relation between the ACE genotype and change in BP depended on baseline sodium excretion ( $\mathrm{P}$ for interaction between baseline 24-h UVNa and change in systolic $\mathrm{BP}=0.059)$. In subjects with higher than sex- and country-specific median of baseline $24 \mathrm{hUVNa}(\approx 167 \mathrm{mmol} / 24 \mathrm{~h})$, carriers of D allele had a higher increase in systolic ( $4.36 \pm 0.72$ vs. $2.34 \pm 1.10 \mathrm{mmHg}$; $\mathrm{p}=0.049)$ and diastolic BP (4.53 \pm 0.52 vs. $3.08 \pm 0.78 \mathrm{mmHg} ; \mathrm{p}=0.044)$ as compared to II homozygotes. Such relation was not observed in subjects with lower-than-median baseline $24 \mathrm{hUVNa}(\mathrm{p} \geq 0.37)$. We did not observe 
any gene-gene interactions among polymorphisms under study. Conclusions: The I/D polymorphisms of the ACE gene influences longitudinal BP change. However, sodium intake seems to modulate this genetic effect.

\section{1 \\ Effect of Blood Pressure on Exploratory Behaviour of Rats in the Open Field Test}

\author{
N. Šestáková1, A. Púzserová1, P. Bališ , P. Slezák1, \\ M. Mach², I. Bernátová ${ }^{1}$ \\ ${ }^{1}$ Institute of Normal and Pathological Physiology, ${ }^{2}$ Institute \\ of Experimental Pharmacology and Toxicology, Slovak \\ Academy of Sciences, Bratislava, Slovakia
}

The aim of this study was to investigate the effect of blood pressure on exploratory behaviour and NO production in the hypothalamus of normotensive Wistar-Kyoto rats (WKY) and borderline hypertensive rats (BHR). Methods: Adult males, 22 weeks old ( $\mathrm{n}=8$ / group) were used in this experiment. Blood pressure (BP) was determined non-invasively by tail-cuff method. NO synthase activity was determined by conversion of $[3 \mathrm{H}] \mathrm{L}$-arginine. Exploratory behaviour was observed in the open field test, size of the arena was $100 \times 100 \mathrm{~cm}$ with a central zone of $55 \times 55 \mathrm{~cm}$. Behaviour was video-traced using a web camera (10 min/session) and analyzed using an ANY-maze videotracking system. Results: BP of WKY and BHR was $104 \pm 2$ and $141 \pm 5 \mathrm{mmHg}$, respectively. Body mass (BM) of WKY and BHR was $427 \pm 8$ and $477 \pm 8$ g, respectively. There were no phenotyperelated differences in NO production. Similarly, no association between NO production in the hypothalamus and BP and BM, respectively, were observed. However, there was a positive correlation between BM and BP $(r=0.62)$. Significant phenotype-related differences were observed in open field exploratory behaviour: BHR were more active than WKY (total distance travelled: $22.6 \pm 2.7$ vs. $15.5 \pm$ $0.85 \mathrm{~m}$; total immobility: $259 \pm 22.8$ vs. $356 \pm 15 \mathrm{~s}$ ). The distance travelled and time spent in the central zone were significantly higher in BHR than in WKY, while no differences were seen in mean or maximal speed of rats. There were correlations between BP and BW, respectively, and total distance travelled, immobility and mean speed. Interestingly, all these correlations were rather closely associated with BP than with body mass, besides the immobility. In conclusion, results suggest that horizontal motor activity of rats in the open field was associated with BP; BHR were more active and spent more time by exploration in the central zone than normotensive rats.

Supported by VEGA grants No. 2/0084/10 and APVV-0523-10.

\section{2 \\ Metabolic Syndrome Increases Aortic Stiffness in Women in Fertile Age}

\section{A. Šimková, J. Bulas, E. Kováčová, A. Reptová}

Ist Department of Internal Medicine, Faculty of Medicine, Comenius University, Bratislava, Slovakia

Background: Metabolic syndrome (MS) frequently occurs in women and its prevalence increases with age. The exact rate of MS differs among different groups studied and is strongly influenced by criteria used for its definiton. We examined a group of women in reproductive age and, using harmonizing criteria for definition, we divided them into groups with and without MS. The protective hormonal status of fertile age was expected to prevent significant differences of vessel wall stiffness. Subjects and Methods: We examined 81 women with a mean age of 40 years; 31 with MS (mean age 41.5 y) and 50 without (39 y, the difference was not significant). Aortic stiffness was examined with an Arteriograph-Tensiomed based on oscillometric measurement and analysis of the shape of brachial pulse wave, giving the aortic pulse wave velocity value among other parameters of hemodynamics. This method determines the global aortic stiffness. Results: The most frequent component of MS was abdominal obesity (93\% vs. $42 \%$ ) , arterial hypertension ( $68 \%$ vs. $10 \%)$ and dyslipidemia ( $29 \%$ vs. $8 \%$ ). BMI was also significantly different $\left(32.3 \mathrm{~kg} / \mathrm{m}^{2}\right.$ vs. $\left.26,5 \mathrm{~kg} / \mathrm{m}^{2}\right)$. The mean value of pulse wave velocity in the group of women with MS was $9.26 \mathrm{~m} / \mathrm{s}$ compared to $7.44 \mathrm{~m} / \mathrm{s}$ in women without MS; the difference was statistically signifficant. Conclusion: Pulse wave velocity as a measure of arterial stiffness was increased in women with metabolic syndrome in comparison to the group of women without it. The presumed protective hormonal status of fertile age did not influence changes of vessel walls leading to increased stiffness attributable to the negative influence of metabolic syndrome. Which component of MS is likely to have the strongest influence remains to be established.

33

\section{Relationships Between Wave Intensity Analysis and Carotid Stiffness}

\author{
D. Škultétyová ${ }^{1}$, S. Filipová ${ }^{1,2}$, B. Liška ${ }^{1}$ \\ ${ }^{1}$ Department of Cardiology, National Institute of \\ Cardiovascular Diseases, ${ }^{2}$ Department of Cardiology, \\ Slovak Medical University, Bratislava, Slovakia
}

The aim of the study is to analyze the parameters of 1) carotid stiffness (CS) and 2) wave intensity (WI). The relationships between $\mathrm{CS}$ and WI may provide information concerning the interaction of the heart and the vascular system. Methods: We investigated 60 patients with arterial hypertension (AH), mean age 59 years. The patients had preserved LVEF and no dilated left atrium. A control group (C) consisted of 22 subjects without cardiovascular disease, mean age 50 years. Ultrasound and echo-tracking were used for the measurement of CS and WI. The measurements were performed on the common carotid artery (CCA). Results: The CS parameters as beta stiffness (beta), index of elasticity (Ep) and pulse wave velocity (PWV) were 
significantly elevated in the AH group (CCA dx: beta $\mathrm{AH}$ group $=9$, beta $\mathrm{C}$ group $=6.9 ; \mathrm{p}<0.01 ; \mathrm{PWV} \mathrm{AH}$ group $=7.2 \mathrm{~m} / \mathrm{s} ; \mathrm{PWV} \mathrm{C}$ group $=6.1 ; \mathrm{p}<0.001 ;$ Ep AH group $=144 \mathrm{kPa} ; \mathrm{C}$ group $=101.5$ $\mathrm{kPa} ; \mathrm{p}<0.001)$. The negative area (NA) value was significantly also higher in the AH group (CCA dx NA: AH group $=50 \mathrm{mmHg} \mathrm{m} / \mathrm{s}, \mathrm{C}$ group $=30,9 \mathrm{mmHg} \mathrm{m} / \mathrm{s} ; \mathrm{p}=0.04)$. In both groups, the correlations between NA and beta, Ep, PWV were negative (PWV and NA AH group: $r=0,35 ; p<0.001 ; C$ group: $r=0.39 ; p<0.001)$. In univariate analysis, correlations between beta, PWV, peak W2, and pre-ejection period were observed only in the $\mathrm{C}$ group. Conclusion: The parameters beta, Ep, PWV and NA were significantly elevated in the AH group. The correlations between NA and CS parameters reflect the influence of arterial stiffness on ventriculoarterial interaction.

34

Long-Term Treatment of Young

Spontaneously Hypertensive Rats with Quercetin Partially Prevented Development of Hypertension

M. Tabačeková M, J. Török, A. Zemančíková, J. Parohová, S. Vranková

Institute of Normal and Pathological Physiology, Centre of Excellence for Cardiovascular Research, Slovak Academy of Sciences, Bratislava, Slovakia

It was suggested that the higher production of reactive oxygen species may contribute to various cardiovascular disorders, including hypertension. The aim of this study was to evaluate the effect of antioxidant therapy with quercetin (a plant-derived flavonoid) on the development of spontaneous hypertension in rats. Methods: Spontaneously hypertensive rats and normotensive Wistar rats, both eight weeks of age, were divided randomly into two groups: 1) a control group drinking just tap water, and 2) a group receiving quercetin $(20 \mathrm{mg} / \mathrm{kg} /$ day) in tap water for the next 4 weeks. Blood pressure was measured weekly by the indirect tail-cuff technique. At the end of the chronic experiment, the rats were killed; body weight and heart weight were determined. The thoracic aorta and mesenteric artery were isolated, suspended in organ baths with modified Krebs solution and connected to a force-displacement transducer for investigating their reactivity under isometric conditions. Concentration of conjugated dienes in selected tissues was measured. Results: At 12 weeks of age, blood pressure was significantly reduced in quercetin-treated SHR compared to untreated SHR, and no reduction in blood pressure was observed in Wistar rats. Relative heart weight was not affected by this treatment. Quercetin administration had no significant effect on the concentration of conjugated dienes in the kidney as well as on the endothelium-dependent relaxation in thoracic aorta of normotensive and hypertensive rats. Contractile responses of the mesenteric artery elicited by exogenous noradrenaline were significantly reduced in quercetin-treated SHR, in contrast to neurogenic contractions, which were not different from that in control SHR. Conclusion: Our results showed that quercetin partially prevented the elevation of blood pressure during hypertension development in SHR. It seems that the antioxidant action may not be the main mechanism involved in the antihypertensive effect of quercetin in SHR.

Supported by VEGA grant No. 2/0193/11.

\section{5}

\section{Pre-Hypertensive Stage Is Associated with Myocardial Up-Regulation of Cell-to-Cell Coupling Protein Connexin-43 and Affected by Dietary Omega-3 Fatty Acids}

\author{
N. Tribulová, J. Radošinská, B. Bačová, V. Knezl, H. Lin, \\ V. Dosenko, J. Navarová, I. Imanaga \\ Institute for Heart Research, Slovak Academy of Sciences, \\ Bratislava, Slovakia
}

Background and Purpose: We have shown previously that the early stage of spontaneous hypertension in rats is characterized by left ventricular hypertrophy, gap junction remodelling and altered expression of the intercellular channels protein connexin-43 (Cx43). These changes deteriorated over time increasing the occurrence of lifethreatening arrhythmias (VF), while they were alleviated by omega-3 fatty acid (omega-3) diet resulting in a decline of inducible VF. The purpose of this study was to explore the possible changes in $\mathrm{Cx} 43$ in pre-hypertensive stage as well as the effect of dietary omega-3. Design and Methods: Experiments were conducted on two models of pre-hypertensive rats, i.e. young male hereditary hypertriglyceridemic rats (HTGR), which exhibited a mild elevation of systolic BP and young male spontaneously diabetic rats (SDR) prior to spontaneous elevation of BP. Age-matched healthy rats were used as well. A part of animals was treated for 2 months with omega-3 $(200 \mathrm{mg} / \mathrm{kg} /$ day). At the end of experiment, biometric and biochemical parameters of all rats were registered. The left ventricular myocardium was processed for determination of $\mathrm{Cx} 43$ mRNA and protein expression using real time PCR and immuno-blotting as well as for the expression of protein kinase C-epsilon (PKC-e), which phosphorylates $\mathrm{Cx} 43$. Key results: Elevated systolic $\mathrm{BP}$ and triglycerides were reduced due to omega-3 diet in HTGR. Compared to healthy rats, there was no significant change in left ventricular weight regardless the treatment. Immunoblotting revealed in all rats three forms of $\mathrm{Cx} 43$ corresponding to functional, phosphorylated forms ( $\mathrm{P}-\mathrm{Cx} 43)$, and the non-phosphorylated (nP-Cx43) form. There were no changes in total Cx43 expression, while P-Cx43 was significantly increased in HTGR and normalized due to omega-3 diet, which in addition enhanced PKC-e expression. Elevation of $\mathrm{CH}$, TG and BG in SDR was significantly reduced due to omega-3. BP and left ventricular weight were neither increased in untreated SDR nor affected by the treatment. Total Cx43 protein and mRNA levels as well as P-Cx43 were significantly higher in SDR than in healthy rats and enhanced due to omega-3. In parallel, the expression of PKC-e was increased in SDR and augmented by treatment. Conclusions: The pre-hypertensive stage of rats, which exhibit elevated triglycerides and blood glucose, is associated with myocardial up-regulation of cell-to-cell coupling protein, connexin- 43 , and it can be modulated by dietary omega-3 fatty acids.

Supported by VEGA 2/0049/09 and APVV SK-UA-0022-09 grants. 
36

\section{Blood Pressure and Vascular Reactivity in Rats Exposed to Continuous Light: Comparison with Other Models of Experimental Hypertension}

\author{
J. Török1, A. Zemančíková1, K. Bednárová1, S. Vranková1, \\ O. Pecháňová1, F. Šimko² \\ ${ }^{1}$ Institute of Normal and Pathological Physiology, Slovak \\ Academy of Sciences, ${ }^{2}$ Institute of Pathophysiology, \\ Faculty of Medicine, Comenius University, Bratislava, \\ Slovakia
}

Objective: Exposure of animals to long-term continuous light, which abolishes nocturnal rise of melatonin in blood, results in hypertension development. In the present study, we analyzed the extent of deterioration of vascular functions in this model and compared it with the vascular impairment in other models of experimental hypertension. Method: Experiments were performed on adult male rats divided into four groups: a) control normotensive Wistar rats; b) Wistar rats exposed to continuous light ( $24 \mathrm{~h} /$ day) for 6 weeks; c) Wistar rats treated with NG-nitro-L-arginine methyl ester (L-NAME) for 6 weeks; d) spontaneously hypertensive rats (SHR). Rings of isolated thoracic aorta and mesenteric artery were suspended in organ baths containing modified Krebs solution and connected to a forcedisplacement transducer for the recording of isometric tension. Nitric oxide (NO) synthase activity in investigated tissues was determined by measuring the conversion of $\mathrm{L}-\left[{ }^{3} \mathrm{H}\right]$-arginine to $\left[{ }^{3} \mathrm{H}\right]$-citrulline. Results: We found that blood pressure was elevated in SHR (192 \pm 3 $\mathrm{mmHg}), \mathrm{L}-\mathrm{NAME}$-treated hypertensive rats $(173 \pm 1 \mathrm{mmHg})$ and in rats exposed to long-term continuous light $(151 \pm 1 \mathrm{mmHg})$ compared to control Wistar rats $(124 \pm 1 \mathrm{mmHg})$. The relative heart weight (heart weight/body weight ratio) was increased in SHR and in L-NAME-treated rats in comparison to control Wistar rats. The exposure of rats to continuous light had no significant effect on the relative heart weight. Endothelium-dependent relaxation was markedly deteriorated in L-NAME-treated rats, less in light-evoked hypertension, and this impairment was partially reversed by the simultaneous captopril administration. Endothelial function was not reduced in SHR in spite of strikingly elevated blood pressure. Sensitivity of smooth muscle in thoracic aorta to exogenous noradrenaline was increased in all three models of experimental hypertension. Adrenergic contractions elicited by electrical stimulation of sympathetic nerves in isolated mesenteric arteries were also significantly increased, mainly in SHR and in L-NAME-treated rats. Exposure of rats to continuous light, as well as L-NAME treatment, did not influence NO synthase activity in the heart and kidney. The NO synthase activity in the heart from SHR was found to be increased. Conclusions: The results indicate that long-term exposure of Wistar rats to continuous light results in a moderate elevation of blood pressure and modification of vascular responses to vasoactive drugs. Our findings obtained in different hypertensive rats revealed enhancement of arterial sympathoadrenergic activity and suggested that alterations in the NO system seem to be specific for the particular models of experimental hypertension.

Supported by VEGA grants No. 2/0193/11 and 1/0187/11.

\section{7}

\section{Gender Differences in the Management of Arterial Hypertension in Patients with Coronary Artery Disease. A Pilot Study}

\author{
A. Vachulová ${ }^{1}$, B.Vohnout ${ }^{3}, J$. Pacák ${ }^{1}$, B. Liška1, \\ S. Filipová ${ }^{1,2}$ \\ ${ }^{1}$ Department of Cardiology, National Cardiovascular \\ Institute, ${ }^{2}$ Department of Cardiology, Slovak Medical \\ University, ${ }^{3}$ Slovak Medical University, Bratislava, Slovakia
}

Higher levels of blood pressure (BP) are associated with continuous increases in the risk for coronary artery disease (CAD) events, beginning at levels below the traditional hypertensive range (normotension, higher normal BP). The relationship between the prevalence of hypertension and traditional cardiac risk factors for CAD in men and women has not been enough studied yet. The aim of the study was to investigate gender differences in management treatment of hypertension. Patients and Methods: We examined 136 patients undergoing coronary arteriography (57 females, 79 males) for suspected myocardial ischemia. Patients were included in a cross-sectional study. Blood pressure, heart rate and BMI were measured using standard methods. Plasma levels of lipids, blood glucose were measured using standard methods. Left ventricular hypertrophy and ejection fraction were detected by echocardiography. General linear model (GLM) was used to evaluate determinants of systolic and diastolic BP using antihypertensive treatment, and sex as covariates. Results: Basic characteristics of patients according to gender are in the table. The two groups differed in systolic and diastolic BP, mean blood glucose, creatinine, total cholesterol (TC), LDL-cholesterol (LDL), triglycerides (TG), but not in TG and HDL-cholesterol (HDL). In GLM using sex, age, arterial hypertension, atrial fibrillation as covariates risk contribution for CAD in men hypertension $(\mathrm{OR}=$ 3.57; 95\% CI 0.66-19.31) and DM (OR = 2.57; 95\% CI 0.67-9.81), $\mathrm{NS}$, in women smoking $(\mathrm{OR}=2.39,95 \%$ CI $0.31-18.65)$. Conclusion: Among patients undergoing angiography for suspected ischemia, elevated SBP and DBP, glycemia and TG were present in female patients. The results suggest that identification of hypertension dictates better control of additional CAD risk factor assessment and management.

Table

\begin{tabular}{lccl}
\hline Sign (units) & Female & Male & $\mathrm{p}$ \\
\hline Age (years) & $62.90 \pm 8.2$ & $66.3 \pm 9.2$ & NS \\
SBP (mmHg) & $147.30 \pm 15.0$ & $140.7 \pm 14.6$ & 0.029 \\
DBP (mmHg) & $86.90 \pm 9.3$ & $84.3 \pm 9.3$ & 0.070 \\
TC (mmol/l) & $5.23 \pm 1.2$ & $5.11 \pm 1.0$ & NS \\
TG (mmol/l) & $3.12 \pm 2.6$ & $2.04 \pm 0.79$ & NS \\
HDL $(\mathrm{mmol} / 1)$ & $1.18 \pm 0.4$ & $1.18 \pm 0.2$ & NS \\
LDL (mmol/l) & $3.57 \pm 1.29$ & $3.48 \pm 0.8$ & NS \\
Creatinine $(\mu \mathrm{mol} / \mathrm{l})$ & $141.54 \pm 93.0$ & $88.93 \pm 25.5$ & NS \\
Glycemia $(\mathrm{mmol} / \mathrm{l})$ & $9.51 \pm 3.4$ & $8.84 \pm 3.3$ & NS \\
\hline
\end{tabular}


38

\section{Effect of Abdominal Obesity on Blood Pressure in Subjects with Comparable Body Mass Index}

\author{
B. Vohnout 1,2,3, J. Franeková3, L. Fábryová3, I. Bugáňová3, \\ A. Molčányováa, H. Pivovarníkováa, E. Rajecová3, \\ J. Sirotiaková3, J. Stavný3 , J. Turay ${ }^{3}$, K. Rašlová1,3 on behalf \\ of MedPed FH Slovakia Collaborative Group \\ ${ }^{1}$ National Reference Centre for Familial \\ Hyperlipoproteinemias, ${ }^{2}$ Department of Physiological and \\ Clinical Nutrition, Slovak Medical University, Bratislava, \\ ${ }^{3}$ MedPed FH Slovakia Collaborative Group, Slovakia
}

Waist circumference has been shown to be related with several cardiovascular risk factors, even in subjects with comparable BMI. The aim of the study was to evaluate the effect of waist circumference on blood pressure in subjects with similar BMI in a large cross-sectional study of 40 years old subjects from general Slovak population. Methods: The study population was stratified into several groups according to a narrow BMI range $\left(1 \mathrm{~kg} / \mathrm{m}^{2}\right)$. Mean systolic (SBP) and diastolic (DBP) blood pressures were compared in each group between those with and without abdominal obesity, separately for men and women. Waist circumference of $\geq 94 \mathrm{~cm}$ in males and $\geq 80 \mathrm{~cm}$ in females defined abdominal obesity. Due to the sample size in each group, only groups from 19 to $30 \mathrm{~kg} / \mathrm{m}^{2}$ were considered for analysis with a total of 2,042 subjects included. The unpaired $t$ test was used to compare mean levels and a $\mathrm{p}<0.05$ was considered statistically significant. Results: Mean values of blood pressure in the groups are in the table. We found higher mean values of systolic and diastolic blood pressure in subjects with compared to those without abdominal obesity, both in men and women (SBP $120.5 \pm 13.3$ vs. $126.1 \pm 15.1$ and 112.3 \pm 12.7 vs. $119.5 \pm 14.5$; DBP $78.5 \pm 8.8$ vs. $82.4 \pm 10.2$ and $73.6 \pm 8.2$ vs. $78.3 \pm 9.6$, men and women, respectively, $\mathrm{p}<0.001$ for all). However, there were no significant differences in blood pressure between subjects with and without abdominal obesity in each BMI group (except of SBP in men with a BMI 23.0-23.9). Conclusion: We did not note differences in blood pressure between subjects with and without abdominal obesity, when subjects with similar BMI were evaluated. However, we cannot exclude that the study had not a sufficient sample size (even though with $>2,000$ subjects) to evaluate very discrete differences that one can expect in subjects with comparable BMI.

\begin{tabular}{llllll}
\hline BMI & Males & & & Females \\
\cline { 2 - 3 } \cline { 5 - 6 } & $\begin{array}{l}\text { Systolic BP } \\
\text { mmHg }\end{array}$ & $\begin{array}{l}\text { Diastolic BP } \\
\mathrm{mmHg}\end{array}$ & & $\begin{array}{l}\text { Systolic BP } \\
\text { mmHg }\end{array}$ & $\begin{array}{l}\text { Diastolic BP } \\
\mathrm{mmHg}\end{array}$ \\
\hline $19-19.9$ & $115.9 \pm 2.9$ & $76.4 \pm 2.3$ & & $109.8 \pm 1.2$ & $71.7 \pm 0.8$ \\
$20-20.9$ & $116.7 \pm 2.3$ & $76.7 \pm 1.4$ & & $110.9 \pm 1.1$ & $72.4 \pm 0.7$ \\
$21-21.9$ & $119.3 \pm 2.0$ & $76.5 \pm 1.2$ & & $114.4 \pm 1.0$ & $74.1 \pm 0.6$ \\
$22-22.9$ & $119.7 \pm 1.6$ & $77.7 \pm 1.0$ & & $113.0 \pm 1.1$ & $74.5 \pm 0.7$ \\
$23-23.9$ & $120.8 \pm 1.5$ & $78.0 \pm 0.9$ & & $115.0 \pm 1.2$ & $74.1 \pm 0.8$ \\
$24-24.9$ & $121.7 \pm 1.3$ & $79.5 \pm 0.9$ & & $115.8 \pm 1.2$ & $75.9 \pm 0.9$ \\
$25-25.9$ & $120.8 \pm 1.2$ & $78.6 \pm 0.8$ & & $118.2 \pm 1.5$ & $77.5 \pm 0.9$ \\
$26-26.9$ & $123.2 \pm 1.4$ & $80.8 \pm 1.0$ & & $115.7 \pm 1.5$ & $76.7 \pm 1.0$ \\
$27-27.9$ & $125.8 \pm 1.3$ & $81.9 \pm 0.8$ & & $115.4 \pm 1.6$ & $76.3 \pm 0.9$ \\
$28-28.9$ & $125.2 \pm 1.9$ & $82.2 \pm 1.2$ & & $117.5 \pm 2.0$ & $76.8 \pm 1.5$ \\
$29-29.9$ & $126.5 \pm 1.7$ & $83.4 \pm 1.1$ & & $122.2 \pm 2.0$ & $81.0 \pm 1.4$ \\
\hline
\end{tabular}

Mean $\pm \mathrm{SE}, \mathrm{BMI}=\mathrm{kg} / \mathrm{m}^{2}, \mathrm{BP}=\mathrm{mmHg}$
39

\section{Adipose Tissue Local RAS Components in Age-Induced and Genetical Rat Models of Obesity}

Š. Zorad, L. Gajdošechová, K. Kršková

Institute of Experimental Endocrinology, Slovak Academy of Sciences, Bratislava, Slovakia

The renin-angiotensin system (RAS) is important in blood pressure control, and results from experimental animals and humans suggest activation of the RAS with obesity and hypertension [Boustany et al. 2004]. However, the effect of particular obesity-induced high caloric diets on hypertension development and activity of adipose tissue RAS is controversial. Therefore, we looked at local RAS parameters in two different rat models of obesity - in age-induced obesity and in obesity of genetic origin. Design and Methods: Male Wistar rats at age of 9, 12, 20, and 26 weeks and 12-week-old lean and obese Zucker rats with mutation in the gene coding for leptin receptor were used to obtain epididymal adipose tissue (EWAT). After decapitation of animals, blood was collected and the prepared serum was used for determination of glucose and hormone (insulin, leptin and adiponectin) concetrations. The EWAT was removed imediatelly and stored at $-70^{\circ} \mathrm{C}$ until analyzing RAS components. The expression of angiotensinogen, ACE and AT1 receptors was evaluated by using real-time PCR and immunoblotting. Results: In Wistar rats, the weight of EWAT and adiposity index increased significantly at 12-, 20- and 26 weeks of age when compared to 9-week-old animals. The serum insulin and leptin concentrations were significantly elevated in 20- and 26-week-old animals. Angiotensinogen and ACE mRNA decreased in parallel with increased age of animals. On the contrary, AT1 receptor mRNA and protein increased with the age of rats. 12-week-old obese Zucker rats display elevated leptin, glucose, insulin as well as adiponectin blood concetrations. Despite some signs of metabolic syndrome and mild hypertension, the expression of local RAS components (angiotensinogen, ACE and AT1 receptor) in EWAT was significantly reduced. The presented results as well as the data from literature suggest that adipose tissue local RAS activity depends on the type of obesity and its stage of development. Local adipose tissue as well as circulating RAS seem to decline with age despite increasing obesity with the exception of AT1 receptors [Krskova et al. 2011]. In obese 12-week-old Zucker rats, circulating as well as local adipose tissue RAS is reduced [Harker et al. 1993, Eckertova et al. 2009]. However, local angiotensin II concentration and AT1 receptor expression in adipose tissue is kept elevated by increasing age of obese Zucker rats [Munoz et al. 2008]. Conclusion: Taken together, it seems that local RAS in adipose tissue is increased only in fully developed obesity and that it might contribute to increasing hypertension.

Supported by grants of Vega 2/0089/11 and APVV SK-PL-0066 ADLIVRAS 


\section{Author Index}

\section{Kidney \\ Blood Pressure \\ Research}

Numbers refer to abstract numbers
Abramović, M. 13

Andriantsitohaina, R. 5

Bačová, B. 1, 4, 23, 26, 28, 35

Bališ, P. 2, 31

Baráková, A. 25

Barančík, M. 9

Bednárová, K. 36

Beňová, T. 4, 23

Bérešová, J. 24

Bernatová, I. 1, 5, 22

Bernátová, I. 2, 31

Bianchi, G. 30

Bilo, G. 15

Bitunjac, M. 13

Bobocká, K. 6

Brand, E. 30

Bugáňová, I. 38

Bulas, J. 32

Casiglia, E. 30

Chňupa, P. 10

Cvitković, A. 13

Čačányiová, S. 7

Čelovská, D. 8

Čertík, M. 26

Čižmárová, E. 20, 25

Dika, Ž. 13

Dosenko, V. 35

Dovinová, I. 9

Eckertová, M. 11

Eisnerová, D. 6

Fábryová, L'. 38

Filipová, S. 10, 33, 37

Filipovsky, J. 30

Franeková, J. 38

Fuček, M. 13
Gajdošechová, L. 9, 11, 39

Gardlik, R. 9

Gerová, M. 7

Imanaga, I. 35

Imrich, R. 18, 20

Jelaković, B. 12, 13

Ježová, D. 11

Jovanović, A. 12

Jurić, D. 13

Jurko Jr. A. 25

Jurkovičová, O. 21

Kalužay, J. 6, 21

Karanović, S. 12, 13

Kawecka-Jaszcz, K. 15, 30

Kellerová, E. 14, 24, 25

Klima, L. 15

Knezl, V. 1, 4, 23, 35

Kopincová, J. 22

Kordić, K. 12

Kos, J. 13

Kováčová, E. 32

Kristek, F. 7

Kršková, K. 11, 18, 39

Kuznetsova, T. 30

Laganović, M. 12

Lin, H. 35

Líška, B. 33, 37

Mach, M. 31

Máleková, M. 7

Malyutina, S. 30

Menne, J. 15

Molčányová, A. 38

Mrazovac, D. 12
Navarová, J. 1, 28, 35

Nikitin, Y. 30

Okša, A. 18

Olszanecka, A. 15

Ondrejčáková, M. 11

Ondrisková, E. 25

Pacák, J. 37

Parohová, J. 34

Pećin, I. 12, 13

Pecháňová, O. 2, 36

Penesová, A. 20

Pivovarníková, H. 38

Podobnik, D. 12

Pokorná, V. 21

Pont'uch, P. 6, 21

Púzserová, A. 2, 5, 22, 31

Rádiková, Ž. 20

Radošinská, J. 1, 4, 23, 35

Rajecová, E. 38

Rašlová, K. 38

Regecová, V. 14, 24, 25

Reptová, A. 32

Seč, P. 26

Seidlerova, J. 30

Sertić, J. 13

Šestáková, N. 31

Šimko, F. 36

Šimková, A. 32

Šimurka, P. 24, 25

Sirotiaková, J. 38

Škultétyová, D. 10, 33

Slezák, J. 4, 23

Slezák, P. 2, 6, 22, 31

Sotníková, R. 28

Sotniková, V. 1

Staessen, J. 30
Stavný, J. 38

Stolarz-Skrzypek, K. 15, 30

Tabačeková, M. 34

Thijs, L. 30

Tikhonoff, V. 30

Török, J. 34, 36

Tribulová, N. 1, 4, 23, 26, 28, 35

Turay, J. 38

Vachulová, A. 10, 37

van Rooyen, J. 1

Viczencz, C. 1

Vlček, M. 20

Vlkovičová, J. 28

Vohnout, B. 37, 38

Vranková, S. 34, 36

Vuković Lela, I. 13

Wojciechowska, W. 15, 30

Željković Vrki, T. 12

Zeman, M. 5

Zemančíková, A. 34, 36

Zorad, Š. 11, 18, 39 